didas de incentivo e desincentivos a determinadas transações tecnológicas, às exportadoras de tecnologia. Estas empresas tornam-se exportadoras de tecnologia à medida em que percebem a impossibilidade de se manterem como exportadora de produtos ou que encontra-se neste canal a primeira e única forma de penetrar num outro mercado. A exportação de tecnologia, conforme já vimos, encerra um processo indutivo de exportação de insumos, componentes, máquinas e equipamentos e serviços técnicos. Infelizmente não se pode pretender que qualquer empresa se transforme rapidamente em exportadora tecnológica. A empresa exportadora de tecnologia, além de possuir pleno controle sobre o seu processo produtivo, deve ter conhecimentos organizados de tal maneira que permitam a sua pronta utilização por outras empresas. Pressupõe um porte industrial avançado, seja econômico ou administrativo.

Por essa razão, no caso brasileiro, seriam poucas as empresas que poderiam se capacitar para tal tipo de transação a curto prazo.

Outro aspecto é que tal empresa deve estar próxima de gerar a sua própria tecnologia ou, meIhor ainda, já possuir autonomia tecnológica. É possível imaginar-se exportar tecnologia anteriormente importada, mas tal ocorrência será mais ou menos viável se a empresa foi capaz de criar alguns aperfeiçoamentos técnicos significativos. Neste último caso, a antiga licenciante pode, inclusive, solicitar que sua licenciada participe da exportação de tecnologia ou vice-versa. Este tipo de negociação pode ocorrer por diversas razões, desde o fato puramente tecnológico até os de base cultural e o de linguagem.

Uma sugestão seria com relação às empresas exportadoras de tecnologias: após a definição do perfil industrial de algumas empresas, e, concluindose pela existência de um potencial de exportação de tecnologia, haveria que se estabelecer um programa de administração dos conhecimentos tecnoló- gicos. Indiretamente, o INPI, já vem dando alguns passos prévios neste sentido; alguns cursos de propriedade industrial para os técnicos de empresas nacionais começam a ser ministrados, como uma forma de motivar a criação de núcleos de patentes e marcas em nossas empresas industriais, assim como, é comum entre empresas norte-americanas, européias e japonesas. Além disso, juntamente com a Escola Interamericana de Administração Pública, temos programado para os próximos três anos cursos para negociadores de tecnologia, os quais, embora voltados para os problemas do importador também podem vir a ser úteis para o caso de exportação. Ainda para este tipo de empresa, quando detectado o seu potencial exportador, deveriam os órgãos de financiamento proporcionar algum tipo de preferência em projetos de desenvolvimento tecnológico.

Do exposto, é lícito concluir que os problemas de exportação de tecnologia são de complexidade bem maior do que as exportações tradicionais, implicando em comércio de outros fatores, a saber: pesquisa e desenvolvimento; alta capacitação de pessoal, tanto em termos quantitativos como qualitativos; e formas de incentivos dentro de uma ótica de longo prazo. Neste caso já se tem programas de governo para formação de pessoal a nível de CNPq, Finep e também de projetos de pesquisas além da área de pessoal, que é o programa do Fundo de Amparo à Tecnologia - Funat, implementado pela Secretaria de Tecnologia Industrial, do MIC.

Em conclusão, é mister esclarecer que a independência tecnológica não é traduzida pela capacidade de exportar ou importar tecnologia, visto que todos os países desenvolvidos, com exceção dos Estados Unidos da América do Norte e ocasionalmente o Japão, são importadores desse insumo; a independência tecnológica deve ser entendida como a capacidade de uma nação selecionar adequadamente as tecnologias a serem adquiridas elou desenvolvidas, objetivando o máximo de efeito econômicosocial.

\title{
Desenvolvimento de tecnologia e penetração no mercado
}

John F. Dealy, advogado, ex-presidente da Fairchild Industry.

John F. Dealy

Gostaria de acrescentar o meu endosso à tese de que a cultura geral que geramos, 
po de contundentes aspectos empresariais que podemos introduzir no nosso sistema são extremamente importantes se quisermos cumprir a tarefa que temos diante de nós, para além dos diferentes elementos institucionais que é necessário colocar para fazer trabalhar todo o sistema. E há que possuir também aquela cultura, aquela liderança, aquela popularidade, tecnicamente qualificada, ativa, agressiva mesmo, aquela fé empresarial que caracterizaram as nações do mundo que o fizeram caminhar para uma mais elevada tecnologia, além da capacidade de fazer tudo isso partindo de quaisquer recursos e ao longo de um limtado período de tempo.

Eu sempre penso que isto é útil, especialmente, uma vez que eu pouco conheço do Brasil e da sua industria e vocês pouco sabem a meu respeito, penso que é útil talvez fornecer alguns exemplos tirados da minha experiência, alguns que eu julgo bem-relevantes em muitos aspectos para aquilo que estamos tentando fazer aqui no Brasil. O primeiro exemplo ou analogia de que eu gostaria de falar é o da companhia de que eu fui associado durante vários anos, a Fairchild Indústrias.

Cerca de dez anos atrás podia dizer-se com verdade que a Fairchild era uma companhia incipiente ou uma empresa pouco desenvolvida da indústria aeroespacial dos EUA. Estávamos obtendo, em vendas, duzentos milhões de dólares aproximadamente em cada ano, numa indústria em que as vendas da maior parte dos líderes ascendiam bem alto nos bilhões. Não possuíamos com o governo o sistema de armas de bașe, o que é um elemento crítico na nossa indústria para atingir o volume tecnológico, nem dispúnhamos dos fundos $P \& D$, todo um sistema, enfim, para se tornar realmente competitivo. Também não possuiamos um programa de aviação comercial de base; construiamos aviões sob licença da Dutch em Fokker e da Swiss em Pilatus e também fabricávamos alguns helicópteros nos anos 60 . De qualquer modo, nos primeiros anos da década de 70 não tínhamos programa privativo de aviação comercial. Dispúnhamos do menor time de engenharia da indústria aeroespacial, situando-nos entre aquelas empresas que estavam ainda lutando por um sistema de armas de base e um programa próprio de aviação comercial.

Em 1972, desenvolvemos, de certo modo, um plano estratégico; Werner von Braun, o homem tão famoso nos EUA, por ter ajudado a incrementar o nosso programa espacial, retirou-se da NASA e se ligou à Fairchild; eu era a esse tempo vice-presidente para o desenvolvimento e requisições e Werner entrou como vice-presidente do desenvolvimento de engenharia. Juntos desenvolvemos o primeiro ver- dadeiro plano estratégico que a Fairchild teve, e pelo que ouvi aqui neste seminário, parece-me que o Brasil está, em muitos aspectos, no mesmo estágio do seu desenvolvimento. Uma das coisas que fizemos nessa época foi tentar avaliar, fria e objetivamente, onde a Fairchild estava forte e onde estava fraca, onde a indústria progredia, qual o tipo de investimento que seria necessário para alcançar os fins que então tínhamos em vista e como poderíamos elaborar um itinerário prático por entre os diferentes obstáculos que divisávamos. Quando apreciamos tudo isso, consideramos que o negócio de subcontrato, de que estávamos vivendo, e que, de certo modo, estava em relação com a nossa manufatura, era um negócio no qual, se quiséssemos crescer, era indispensável a seleção, de modo a que cada subcontrato de fabrico aeronáutico que assinássemos tinha de nos ensinar algo. Ele teria, ou nos ensinar um novo processo, ou nos habilitar a manejar uma peça de material de outra dimensão, ou nos capacitar para associar um sistema de um jeito diferente daquele que vínhamos praticando, tudo de modo a que cada especial subcontrato nos promovesse tecnicamente; e ainda que não assistíssemos ao planejamento e desenvolvimento do projeto, estávamos usando o subcontrato como base para manter os elementos críticos e funcionais da nossa tecnologia pelo menos consciente do que estava ocorrendo na indústria.

Sentimos que tínhamos de fazer um investimento que fosse além de um sistema primário de armas aéreas e vencer essa fase. Tínhamos de pegar o nosso time de engenharia, aumentá-lo nas áreas em que estivesse fraco, aplicar as limitadas capacidades de investimento que a companhia tinha e forçar uma abertura de modo a não ficarmos sempre como seguidores, mas manobrar, para seguir em frente e alcançar um sistema primário de fabrico. Precisávamos explorar a indústria aeroespacial e encontrarmos uma linha de produtos da envergadura, da complexidade técnica e, podemos dizê-lo, da estatura da capacidade fabril que a Fairchild podia proporcionar, de modo que pudéssemos assumir essa nova face e crescermos, pondo de lado a primária aviação comercial. Constatamos, todavia, que isso não era suficiente para a nossa companhia, visto que o espaço aéreo era um campo demasiado limitado, demasiado cíclico, com seu altos e baixos (por paradoxal que isso possa parecer...), dependendo muito dos orçamentos da defesa, sendo assim um negócio condicionado à atividade aérea, e que, para que a nossa empresa crescesse e se tornasse realmente um fator mais significativo no campo de negócios americano era indispensável penetrar em algumas áreas que não ficassem tão dependentes dos mesmos ciclos econômicos e não carecessem, muito francamente, do mesmo constante investimento exigido pelo espaço aéreo. Procuramos então um se- 
tor industrial e comercial, uma linha de produtos correntes comercial e industrialmente e resolvemos fazer um teste no sentido de que o negócio que procurávamos nos permitisse um comando de mercado mercê da aplicação da tecnologia que a Fairchild estava desenvolvendo no programa aeroespacial, mas onde não tínhamos uma boa capacidade de marketing; assim, mesmo usando uma tecnologia mais simples nessa outra área, poderíamos desfrutar de um negócio de melhor fluxo de caixa e no qual, pelo menos, possuíssemos boa participação no mercado.

A seguir concluimos, com a simplicidade exigida por todos os bons planos, que na atividade de longo prazo precisávamos, desde já, iniciar os investimentos para podermos garantir uma posição de liderança nessa área de grande expansão dentro dos dez a vinte anos vindouros. De outro modo, estaríamos dispendendo toda a nossa energia negocial e correndo para uma disputa com outrem. Assim, tínhamos de achar uma área que ainda não estivesse dominada, ou onde a tecnologia mudasse tão rapidamente que pudéssemos entrar e aplicar a nossa especialidade e desenvolver um quadro de pessoal, alcançando uma posição de liderança, ou então, ainda, uma área onde o crescimento fosse tão rápido que permitisse campo para muitos debutantes. A área que então selecionamos foi a das comunicações por satélite ou comunicações digitais de alta velocidade, visando realmente um longo prazo na transmissão rápida de dados e utilizando satélites e sofisticado equipamento de base. Um negócio, digase de passagem, em que, para além de alguns projetos técnicos para a NASA não possuíamos bases, nem experiência, nem pessoal e que calculamos que nos levaria dez anos pelo menos para empatare uns vinte para dar dinheiro e que iria absorver provavelmente um bom par de centenas de milhões de dólares do capital da Fairchild para poder acontecer.

Vejamos agora a perspectiva e as proposições naquela hora. Como disse, a Fairchild estava fazendo naquela data dois milhões de dólares de vendas totais anuais, o seu lucro médio era de cerca de sete milhões por ano. O seu valor líquido andaria por volta de quarenta a quarenta e cinco milhões e os seus débitos bancários orçavam pelos noventa milhões. Era, portanto, um ambicioso plano na hora em que se iniciou. Ao longo dos anos fomo-lo incentivando e, como um bom plano, fomos mantendo os conceitos simples com que começamos, continuando a ajustar tudo, entretanto, com vista a enfrentar as realidades do mercado e da situação para que caminhávamos. E conseguimos levar tudo a bom termo.

Ao longo de todos esses anos eu ocupei diferentes posições na companhia, tendo chegado a presidente em 1976. Em 1981, a Fairchild estava faturan- do um bilhão e três milhões de dólares em vendas. Tivemos a mais elevada taxa de lucro da indústria espacial durante os cinco anos de 1976 a 1981, não obstante o fato de nessa ocasião a nossa empresa de satélites americanos, iniciada em 1972, com um investimento de cerca de cem milhões de dólares, não estar fazendo dinheiro, e o outro fato de que ainda estamos investindo a fundo nos projetos do espaço aéreo, pelo que não podíamos retirar donde é necessário, limitando-nos a fixar um plateau. Para além de tudo isso, estamos atravessando duros tempos econômicos nos EUA, presentemente. Assinalo este ponto porque é da minha experiência pessoal e julgo que pode ser bastante útil para um país como o Brasil e para vocês, que me escutam, examinar o problema, uma vez que eu acredito que, como é óbvio, existem enormes recursos nesta terra: vocês dispõem de um tremendo quadro de pessoal, que pode ser mobilizado e nós vemos hoje um mundo com uma série de problemas neste campo; assistimos aos problemas do financiamento a curto prazo, vemos toda a sorte de incertezas que avassalam o mundo, mas o teste real da nossa habilidade para seguir em frente na indústria de tipo tecnológico é uma cuidadosa seleção dos mercados em que se está entrando, uma acurada manipulação dos recursos atinentes ao cumprimento da tarefa e tudo isso antes de começar, pois o melhor plano do mundo não funcionará se os recursos para isso não forem captados antes. É indispensável um investimento pré-frontal. Não funciona dizer: "vamos ter um ingresso positivo por ano em qualquer ramo", porque não vai dar certo. Tem que se fazer um plano equilibrado no qual alguns setores do negócio poderão gerar ingressos de caixa, outros, segundo o nosso plano de crescimento só terão um retorno a longo prazo e outros ainda a médio prazo.

Não tem nada de errado em admitir tecnologia de outros países; a Fairchild fez isso durante anos, adotando tecnologia da Europa e de todos os EUA. Desde que se tenha uma finalidade nessa adoção e uma vez que dela se tire proveito e conhecimento, tal como aconteceu nos três exemplos que eu gostaria de lhes dar e que constituem uma aventura conjunta que tivemos ao longo dos anos, os quais ilustram, segundo julgo, os diferentes níveis em que se pode fazer algo nessa adoção e nesse âmbito de transferência tecnológica, além dos problemas que com isso se relacionam.

A primeira experiência foi bem direta. Em meados de 1970 contratamos os japoneses para fazerem assentos de avião para nós; a Fairchild era então um elemento significativo no mercado mundial de assentos aéreos. Foi uma concessão arrojada, uma vez quer os japoneses estavam no negócio de assentos, mas só de ônibus e trens e não para a aviação. $\mathrm{O}$ interesse da Fairchild era porque ainda não havíamos 
sido capazes de penetrar o mercado do extremooriente, quer no Japão, quer em outros países, não-obstante a aviação estar comprando largamente nos EUA. Assim, o conceito básico do trato era que os japoneses construiríam com a nossa marca, inicialmente. Não havia pagamentos pré-frontais neste acordo, dado que estávamos penetrando um mercado onde não tínhamos realmente qualquer investimento e não sabíamos ainda qual o êxito a obter nele. Os japoneses, por seu lado, também não estavam em condições de nos fazer um substancial pagamento pré-frontal por aquilo que era apenas tecnologia em potencial e mais know-how de processo de fabrico e do detalhe de desenho que nós possuíamos. Ao mesmo tempo, não deixávamos de reconhecer que haveria problemas inerentes num acordo de fabrico com os japoneses, naquele estágio. Em primeiro lugar, uma relutância por parte das instituições japonesas em nos pagarem royalties; em segundo lugar, a dificuldade de contabilizar o que iria realmente acontecer em termos das vendas que seriam feitas ou do custo que os japoneses teriam de suportar. Entramos assim num acordo muito simples, que foi o de eles mandarem um time para aprender como fabricar o assento. Por nosso lado, enviamos também um time para verificar se o assento estava sendo construído capazmente, porque, afinal, ele tinha a nossa marca e estava sendo vendido para companhias que tinham vários problemas e requisitos de segurança, obviamente. 0 royalty que nos era devido era pago por assento e fixado antecipadamente em dólares e não em percentual sobre os custos ou qualquer outra coisa. Era um número certo de dólares por assento. A única obrigação dos japoneses era a de que, se eles introduzissem melhorias no assento, nós receberíamos o benefício dessas beneficiações. Eles tinham limitações no seu mercado, prescrevendo até onde podiam ir vender os assentos, mas com essa aliança, que tivemos com eles, julgo que por dez anos, nós possuimos agora uma avançada linha de assentos, que oferecemos em condições bem diferentes. $\mathrm{O}$ efeito disso foi mutuamente benéfico, mesmo depois de ter havido muita argumentação sobre diferentes elementos e pontos. Os japoneses tornaram-se fabricantes de assentos muito competentes, experimentados e por baixo custo; por nosso lado, nós tivemos uma larga penetração num mercado que de outro modo não teríamos conseguido penetrar.

Ao mesmo tempo houve melhorias que os japoneses introduziram e a cada ano íamos ver os assentos que eles estavam efetivamente fabricando e deixávamo-los vir olhar aqueles que nós produzíamos. O que eu pretendo salientar neste acordo é que não é realmente a alta tecnologia que conta, mas sim que cada parte receba benefícios e eu sempre acreditei que num acordo de autorização de fabrico, se se estabelece apenas aquela via única - eu te autorizo e ensino a minha tecnologia e você me paga uma renda - isso geralmente ao fim dum período longo não funciona mais para ambas as partes. $\mathrm{O}$ autorizado e recipiendo da tecnologia tem de extrair dela alguma coisa, aumentando a sua capacidade de fabrico e penetrando nessa nova área tecnológica, mas também o autorizante precisa de tirar do acordo algo mais além da renda e o melhor que ele pode obter é geralmente a penetração de um mercado onde ele de outro modo não conseguiria ocupar lugar significativo.

O segundo pacto a que eu gostaria de fazer referência é um que foi muito complicado, envolveu muitos países e se prolongou por vários anos: foi o programa de licenciamento por todo o mundo do programa do rifle $\mathrm{M}-16$, que foi um invento da Fairchild dos anos 50 e sofreu várias melhorias patenteadas nos anos subseqüentes, sendo certo que a Colt, nos EUA era nosso licenciado. Tivemos depois uma série de sublicenças que eu negociei nos anos 60 e 70, tendo cooperado com a Colt nas suas negociações das mesmas.

A importância desses contratos em oposição aos outros de que falei primeiro é a de que a manufatura de assentos de avião não exige substanciais investimentos e assim os japoneses não precisaram de fazer grandes investimentos de base para construir o assento, enquanto que instalar uma fábrica para manufaturar rifles é um empreendimento extremamente caro, requerendo uma boa parte de tecnologia específica e um completo sistema no local. Por isso, neste caso, não negociávamos com uma determinada companhia como no Japão, mas sim com vários governos estrangeiros, tais como a Coréia, as Filipinas, Singapura e cada contrato tinha de ser cuidadosamente manejado. Mas de novo o ponto importante era que o benefício para a Colt para além de receber a renda, que partilhava conosco, se cifrava na penetração de mercados que de outro modo não conseguiria atingir. As vantagens resultantes para o país variavam de um para outro. Em um país estavam simplesmente interessados em empregar pessoal, sabiam que tinham de adquirir rifles e então a condição dessa aquisição era a implantação duma fábrica no próprio país; em outro havia um claro desejo de entrada no negócio do armamento e por isso pretendiam obter um rifle moderno e, embora tivessem de enfrentar o custeio de um investimento de base substancial para conseguir assistência técnica e os dados imediatos e a longo prazo, eles esperavam obter com isso tecnologia suficiente para entrar no negócio de armas.

O país estava numa posição dupla: tinha por um lado uma grande necessidade interna de rifles, sobretudo para as forças armadas; ao mesmo tem- 
po, estava querendo construir indústrias pesadas e estava assim utilizando esta oportunidade como um método para reforçar a sua própria. Surgiam vários tipos de problemas nesses acordos por se estar tratando agora com governos estrangeiros, o que levantava questões de como contabilizar os livros no caso de haver dúvidas quanto aos custos. Por isso, nesses acordos, para a coisa poder funcionar como devia, havia sempre substanciais pagamentos prévios: pagamentos para a assistência técnica, etc. E existiam ainda todas as espécies de fórmulas complicadas quanto ao royalty especial por rifle no correr do tempo e tínhamos também sistemas mediantes os quais fornecíamos peças a esses países durante um certo período, o que nos posicionava bem dentro do acordo, com a compensação na mão por parte do autorizante até que o país se achasse realmente em condições de construir um rifle completamente por seus próprios meios. Acho que é preciso ter muito cuidado com isso nos acordos de concessão. Quando se vai ter o retorno econômico no decorrer de um longo período de tempo, o autorizante quererá, realisticamente, assegurar-se desse adequado retorno, ou por antecipação ou por outra forma contratual, antes de colocar de fato outrem no negócio e que o possa gerir daí em diante.

O terceiro acordo a que quero me referir rapidamente é aquele que na realidade considero a fase seguinte em sofisticação no plano de negócio da Fairchild, em 1972. Consideramos que, se realmente queríamos crescer na indústria aeroespacial, não o poderíamos fazer sós. Tínhamos de firmar alianças para entrar na aventura conjunta e fazer as coisas com outros interessados. Em 1980, na seqüência de dezoito meses de trabalho e deliberações e significativos investimentos de base por ambos os lados, entramos numa mais volumosa aventura conjunta com a Scania AB-SAAB, da Suécia, para planificar, desenvolver, fabricar e negociar por todo o mundo um novo avião comercial. De ambos os lados se considerou que o projeto era tão grandioso, os riscos tão grandes e o mercado tão aleatório, perante os dados computarizados, que se tornava mais sensato partiIhar o risco de seguir em frente e, de novo, se puseram várias razões de ambas as partes. $O$ pessoal da $\mathrm{SAAB}$ dispunha de capacidade em engenharia resultante dos seus programas militares; a Fairchild possuía basicamente o seu pessoal técnico ligado aos projetos, mas só iríamos dispor de capacidade de produção em meados de 1980; tínhamos, no entanto, uma linha de aviação comercial na nossa subsidiária Swarangen. Eles não tinham aviação comercial, mas queriam entrar no ramo e então nós trabalhamos até que finalmente conseguimos uma plataforma de termos e condições que refletiam as reais necessidades e objetivos das duas partes. Aí, partiIhávamos a produção mediante uma fórmula de divisão de custos e, ainda, segundo uma outra fórmula, porque, como disse, dispúnhamos de maior capacidade de produção do que de engenharia, tínhamos companhias de mercado separadas, formadas para este empreendimento custado conjuntamente pelas nossas duas empresas e onde nós auferíamos proveitos na companhia de mercado num percentual diferente do das outras áreas. Um acordo muito complicado, no qual uma tremenda dose de energia e despesa ocorreu nos primeiros estágios, antes que finalmente fosse assinado para assim se ter certeza de que correspondia aos objetivos de ambas as partes e era viável. Isso permitiu à SAAB penetrar numa área tecnológica em-que estava por fora - a moderna aviação comercial - e permitiu à Fairchild aumentar mais rapidamente as suas linhas de aviação comercial e ter ainda uma melhor penetração no mercado mundial.

\section{Desenvolvimento de tecnologia própria. Áreas selecionadas de investimentos}

Ozílio Carlos da Silva, diretor comercial da Empresa Brasileira de Aeronáutica S/A -

Embraer.

Obviamente, quem produz um produto tecnologicamente avançado, como é o caso da Embraer, que enfrenta pesada competição no mercado internacional, e que age numa área de rápida evolução 